\title{
Effect of medroxyprogesterone on arterial blood gases, leptin and neuropeptide $Y$ in postmenopausal females
}

\author{
T. Saaresranta*,\#, K. Irjala", O. Polo*,\#
}

Effect of medroxyprogesterone on arterial blood gases, leptin and neuropeptide $Y$ in postmenopausal females. T. Saaresranta, K. Irjala, O. Polo. (C) ERS Journals Ltd 2002. ABSTRACT: Natural progesterone, a potent respiratory stimulant, stimulates leptin production in premenopausal females. Leptin and its counterpart neuropeptide Y (NPY) have recently been linked with respiration. The effect of medroxyprogesterone acetate (MPA) on arterial blood gases, serum leptin and NPY was evaluated in this study.

Fourteen postmenopausal females with respiratory impairment, due mostly to chronic obstructive pulmonary disease, were recruited for a randomised, double-blind, placebocontrolled crossover trial. Arterial blood gases, serum leptin and NPY concentrations were measured at baseline and after 14 days of treatment with placebo and MPA, separated by a 6-week washout period.

Thirteen patients completed the trial. The mean \pm SD carbon dioxide tension in arterial blood $\left(\mathrm{Pa}_{\mathrm{a}}, \mathrm{CO}_{2}\right)$ was $5.4 \pm 0.6 \mathrm{kPa}$ at baseline, and decreased by $0.8 \pm 0.3 \mathrm{kPa}$ during treatment with MPA. The oxygen tension in arterial blood $\left(\mathrm{Pa}_{\mathrm{a}} \mathrm{O}_{2}\right)$ and $\mathbf{p H}$ did not change. At baseline, the mean base excess was $0.6 \pm 1.9 \mathrm{mmol} \cdot \mathrm{L}^{-1}$ and the mean bicarbonate $\left(\mathrm{HCO}_{3}{ }^{-}\right)$concentration was $25.1 \pm 1.6 \mathrm{mmol} \cdot \mathrm{L}^{-1}$. With MPA, base excess decreased by $2.2 \pm 1.2 \mathrm{mmol} \cdot \mathrm{L}^{-1}$ and $\mathrm{HCO}_{3}^{-}$by $1.9 \pm 1.0 \mathrm{mmol} \cdot \mathrm{L}^{-1}$ from baseline. The mean concentrations of serum leptin $\left(19.8 \pm 9.9 \mu \mathrm{g} \cdot \mathrm{L}^{-1}\right.$ at baseline, $19.7 \pm 9.8 \mu \mathrm{g} \cdot \mathrm{L}^{-1}$ with MPA) or NPY $\left(94.0 \pm 18.3 \mathrm{pmol} \cdot \mathrm{L}^{-1}\right.$ at baseline, $85.1 \pm 41.2 \mathrm{pmol} \cdot \mathrm{L}^{-1}$ with MPA) did not change. However, the reduction in $\mathrm{Pa}_{\mathrm{a}} \mathrm{CO}_{2}$ correlated with the reduction of serum leptin concentration.

Medroxyprogesterone acetate effectively decreased the carbon dioxide tension in postmenopausal females with chronic respiratory impairment. The results suggest that a decrease in the carbon dioxide tension of $\geqslant 0.9 \mathrm{kPa}$ is necessary for a reduction in serum leptin concentration.

Eur Respir J 2002; 20: 1413-1418.
Depts of *Pulmonary Diseases, "Physiology and "Clinical Chemistry, Turku University Central Hospital and University of Turku, Turku, Finland.

Correspondence: T. Saaresranta, Dept of Pulmonary Diseases, Turku University Central Hospital, Kiinamyllynkatu 4-8, FIN-20520 Turku, Finland. Fax: 35823133328

E-mail: tarja.saaresranta@tyks.fi

\section{Keywords: Breathing}

chronic obstructive pulmonary disease hypercapnia

leptin

neuropeptide $\mathrm{Y}$

progesterone

Received: September 202001

Accepted after revision: July 72002

This work was supported by grants from the Finnish Medical Foundation, the Finnish Anti-Tuberculosis Association Foundation, the Väinö and Laina Kivi Foundation and the Turku University Foundation.
Breathing is regulated through voluntary (cortex) and involuntary (emotional, metabolic, neural and endocrine components) control mechanisms. Furthermore, the endocrine and nervous systems have complex interactions. Although some endocrine links with breathing are well established, a comprehensive understanding of the interactions of hormones and breathing is lacking.

Leptin and neuropeptide Y (NPY) regulate food intake, but are also involved in other functions. Recent data suggests that leptin may increase ventilation [1], whereas NPY has the opposite effect [2, 3]. Leptin inhibits NPY expression [4]. In premenopausal females, natural progesterone stimulates leptin release $[5,6]$.

Postmenopausal females have lower leptin levels [7, 8] and higher NPY levels [9] than premenopausal females. After the menopause, females frequently gain weight. They also have an increased prevalence of sleep-disordered breathing [10]. This increase has been attributed to the decline in serum progesterone concentrations, since progesterone is a potent respiratory stimulant. Alterations in serum leptin levels have also been linked with alterations in female hormone concentrations, i.e. progesterone [11].
Progestins are frequently used as a part of postmenopausal hormone replacement therapy. A synthetic progesterone derivative, medroxyprogesterone acetate (MPA), effectively stimulates breathing in postmenopausal females [12] and produces some improvement in sleep-disordered breathing in such individuals $[13,14]$. The exact mechanisms through which progestins stimulate breathing are not known. MPA is considered to be a central respiratory stimulant [15] but there is also evidence for peripheral action [16]. MPA induces complex endocrine alterations, which seem to be associated with breathing [17]. The effect of plain progestin therapy on leptin or NPY levels is not known. The effects of short-term treatment MPA on arterial blood gases, serum leptin and NPY levels in postmenopausal females with respiratory impairment were investigated in this study.

\section{Subjects}

Fourteen postmenopausal females with constant or episodic hypercapnic or hypoxaemic respiratory impairment were recruited for the trial. Their respiratory 
impairment was due to chronic obstructive pulmonary disease (COPD) $(n=11)$, end-stage asthma or late sequelae of pulmonary tuberculosis. Their mean age \pm SD was $68.1 \pm 7.9$ yrs and their mean body mass index (BMI) $26.6 \pm 6.1 \mathrm{~kg} \cdot \mathrm{m}^{-2}$. The postmenopausal state was confirmed by measurement of serum follicle stimulating hormone $(\mathrm{FSH})$ concentration over $30 \mathrm{IU} \cdot \mathrm{L}^{-1}$.

The subjects were strictly requested not to use any medication affecting the central nervous system, alternative therapy or any hormone replacement therapy except the study drugs. Subjects using long-term oxygen therapy, with cancer, psychiatric, neurological, thromboembolic or hepatic diseases, renal failure, unstable hypertension, severe rheumatoid arthritis, insulin-dependent diabetes or severe hyperlipidaemia (total serum cholesterol $>9.5 \mathrm{mmol} \cdot \mathrm{L}^{-1}$ or serum triglycerides $>2.5 \mathrm{mmol} \cdot \mathrm{L}^{-1}$ ) were excluded. One subject who smoked less than five cigarettes per day was advised not to smoke during the $9 \mathrm{~h}$ preceding each study visit. All other subjects were current nonsmokers.

\section{Methods}

The study followed a double-blind randomised placebo-controlled crossover design and included three visits (fig. 1). There was a 6-week washout period between the 2-week placebo and MPA treatment periods. The choice of a 6-week washout period was based on a previous study, where, in a slightly younger postmenopausal female population, 6 weeks were
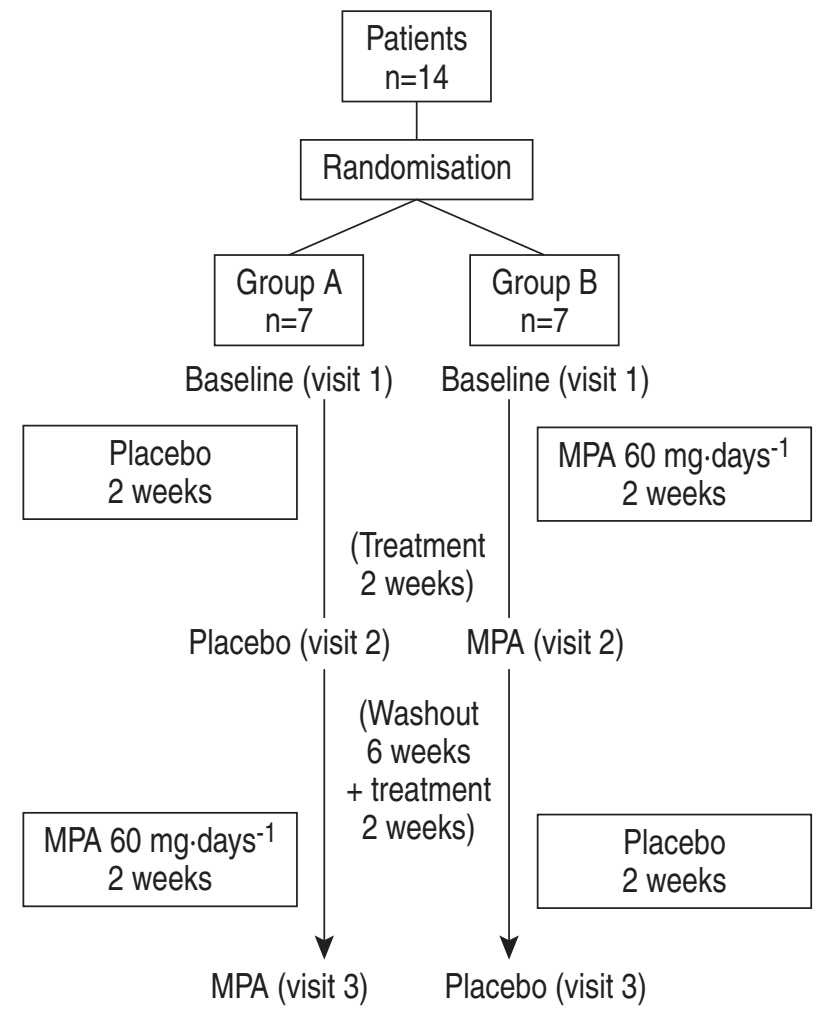

Fig. 1.-Flow diagram of the study. MPA: medroxyprogesterone acetate. needed for all the measured variables to return to baseline after cessation of MPA [12]. The same visit protocol was followed at baseline, after a 2-week placebo and a 2-week MPA $\left(60 \mathrm{mg} \cdot \mathrm{day}^{-1}\right)$ period (Lutopolarß); Orion Pharma, Espoo, Finland). The placebo tablets were identical in appearance to the MPA tablets and were provided by the same manufacturer. The visit protocol included measurements of weight, arterial blood gases, serum concentrations of leptin, NPY and alanine aminotransferase, blood haemoglobin and flow volume spirometry (VMAX 22D; Sensor Medics, Boulder, CO, USA). The subjects had at least a 15-min rest period in the sitting position before the blood samples were obtained after overnight fasting. Subjects kept a diary of their symptoms and possible adverse events for the 14 days prior to each visit.

The blood samples were drawn at 07:00 $\mathrm{h}$ and flowvolume spirometry was measured within a 1 -h period proceeding this. Arterial blood samples were obtained from a single arterial puncture in the patients in the sitting position, and were analysed immediately using a blood-gas analyser (Ciba-Corning 865 R); Ciba corning, Sudbury, UK). Serum concentrations of FSH were measured by time-resolved immunofluorometric assay (Autodelfia $\mathbb{R}$; Wallac, Turku, Finland), alanine aminotransferase by enzymatic methods (Hitachi 717 (R); Hitachi, Tokyo, Japan), and haemoglobin concentration by an appropriate laboratory device (Coulter STKR B); Coulter Corp, Hialeah, FL, USA). For serum leptin and NPY measurements, serum was separated immediately after blood sampling and kept frozen at $-70^{\circ} \mathrm{C}$ until analysed. Serum leptin was measured using a human leptin radioimmunoassay (RIA) kit (Linco Research Inc., St Charles, MO, USA). Serum NPY was measured by Euria-NPY ( RIA kit (Euro-Diagnostica AB, Malmö, Sweden). Compliance was assessed by tablet counts and patient reviews.

All patients gave written informed consent. The study protocol was approved by the Joint Commission on Ethics of Turku University and Turku University Central Hospital, and by the National Agency for Medicines.

\section{Statistical analyses}

The results were analysed using statistical methods developed for a crossover design of two treatments and two periods [18]. First any carryover effect was identified using analysis of variance of repeated measurements according to JONES and KENWARD [18], performed with the MIXED procedure. The testing for a carryover effect evaluated whether there was any residual effect of MPA on measured variables after a 6-week washout. The period effect tested whether the order of placebo and active drug had any effect on the results. A $p<0.1$ was considered significant for a carryover effect, whereas a $\mathrm{p}<0.05$ was considered significant for period and treatment effects. Distribution and variance for each parameter were tested. The study sample was also analysed as a single placebo controlled study, and paired comparisons of differences ((placebo-baseline) versus (MPA-baseline)) were 
made. Depending on the distributions of differences ((placebo-baseline) and (MPA-baseline)), either a paired t-test (in parametric cases) or Wilcoxon Signed-Rank test (in nonparametric cases) were used. The correlations for serum leptin and NPY levels with BMI and arterial blood gases were tested at each of the three time points (at baseline, with placebo and with MPA) using Spearman's or Pearson's correlation coefficients, as applicable. The p-values were corrected according to the Bonferroni principle. Correlations between changes in serum leptin and NPY levels and other parameters were tested using Spearman's or Pearson's correlation coefficients, as applicable.

\section{Results}

Thirteen patients completed the study protocol. One patient discontinued due to an exacerbation of COPD. No carryover effect on the measured parameters was observed. A period effect was seen in the carbon dioxide tension in arterial blood $\left(\mathrm{Pa}, \mathrm{CO}_{2}\right)$, the values being higher during the second period. The mean weight remained unchanged throughout the study. At baseline the mean forced expiratory volume in one second (FEV1) was $1.0 \pm 0.5 \mathrm{~L}(44 \pm 19 \%$ of predicted) and the mean forced vital capacity (FVC) was
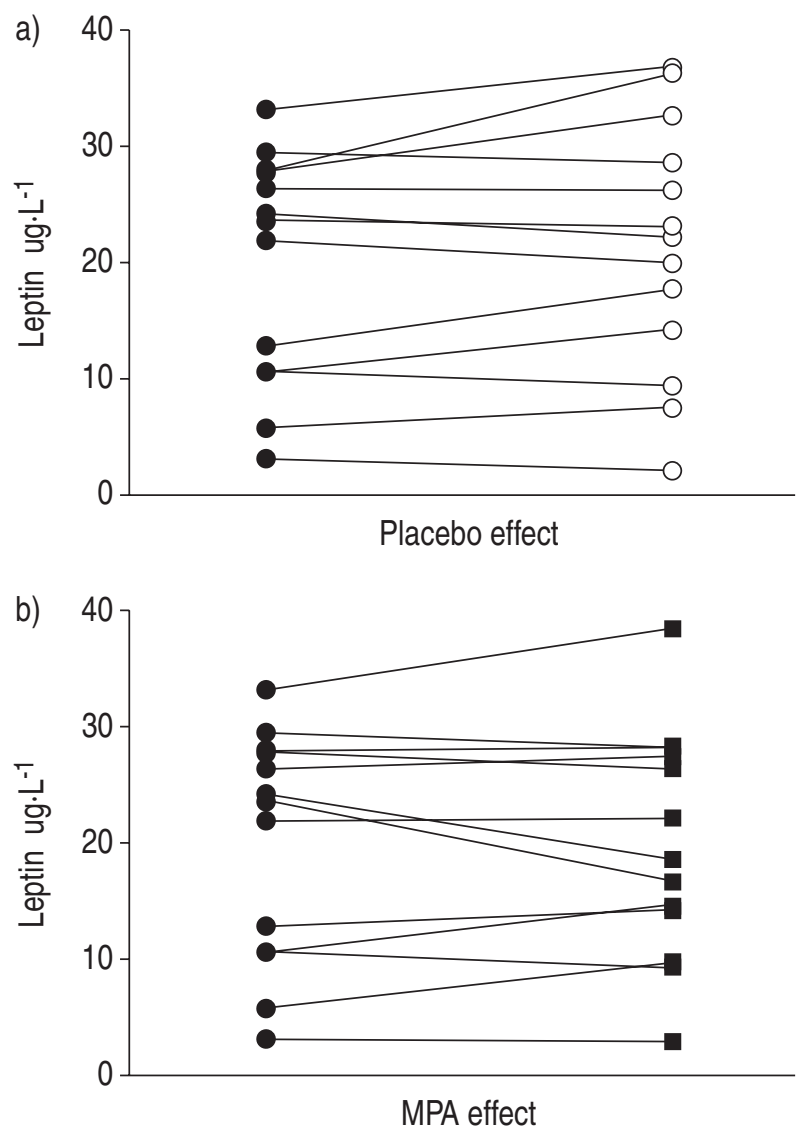

Fig. 2.-Serum concentrations of leptin at baseline, with a) placebo and b) after 2-weeks of treatment with medroxyprogesterone acetate (MPA). baseline values; $\bigcirc$ values with placebo; values with MPA.
$1.7 \pm 0.6 \mathrm{~L}(61 \pm 23 \%$ pred $)$. Both FEV1 and FVC remained unchanged throughout the study. Blood haemoglobin (baseline mean $137.8 \pm 9.7 \mathrm{~g} \cdot \mathrm{L}^{-1}$ ) or serum alanine aminotransferase (baseline mean 17.7士 $6.0 \mathrm{U} \cdot \mathrm{L}^{-1}$ ) were within reference ranges and did not change during the trial. No adverse drug effects were observed or reported.

The mean $P \mathrm{a}, \mathrm{CO}_{2}$ was $5.4 \pm 0.6 \mathrm{kPa}$ at baseline and decreased on average by $0.8 \pm 0.3 \mathrm{kPa}$ with MPA $(\mathrm{p}<0.001)$. The mean oxygen tension in arterial blood $\left(P \mathrm{a}, \mathrm{CO}_{2}\right)$ was $1.3 \pm 1.6$ and did not change significantly during the study period. At baseline, the mean $\mathrm{pH}$ was $7.41 \pm 0.03$, the change with MPA $(0.01 \pm 0.03)$ was not significant. At baseline, the mean base excess (BE) was $0.6 \pm 1.9 \mathrm{mmol} \cdot \mathrm{L}^{-1}$ and the mean $\mathrm{HCO}_{3}^{-}$ was $25.1 \pm 1.6 \mathrm{mmol} \cdot \mathrm{L}^{-1}$. With MPA, BE decreased by $2.2 \pm 1.2 \mathrm{mmol} \cdot \mathrm{L}^{-1}(\mathrm{p}<0.0001)$ and $\mathrm{HCO}_{3}^{-}$by $1.9 \pm$ $1.0 \mathrm{mmol} \cdot \mathrm{L}^{-1}$ from baseline $(\mathrm{p}<0.0001)$.

The mean concentrations of serum leptin (fig. 2) or NPY (fig. 3) did not change. At baseline, mean serum leptin concentration was $19.8 \pm 9.9 \mu \mathrm{g} \cdot \mathrm{L}^{-1}$. On MPA, leptin was $19.7 \pm 9.8 \mu \mathrm{g} \cdot \mathrm{L}^{-1}$. At baseline, mean serum NPY concentration was $94.0 \pm 18.3 \mathrm{pmol} \cdot \mathrm{L}^{-1}$. On MPA, $\mathrm{NPY}$ was $85.1 \pm 41.2 \mathrm{pmol} \cdot \mathrm{L}^{-1}$.

When treated as a single-group placebo-controlled trial, the level of significance further increased the change in $\mathrm{Pa}_{2} \mathrm{CO}_{2}(\mathrm{p}=0.0001)$, while that for $\mathrm{Pa}, \mathrm{O}_{2}$
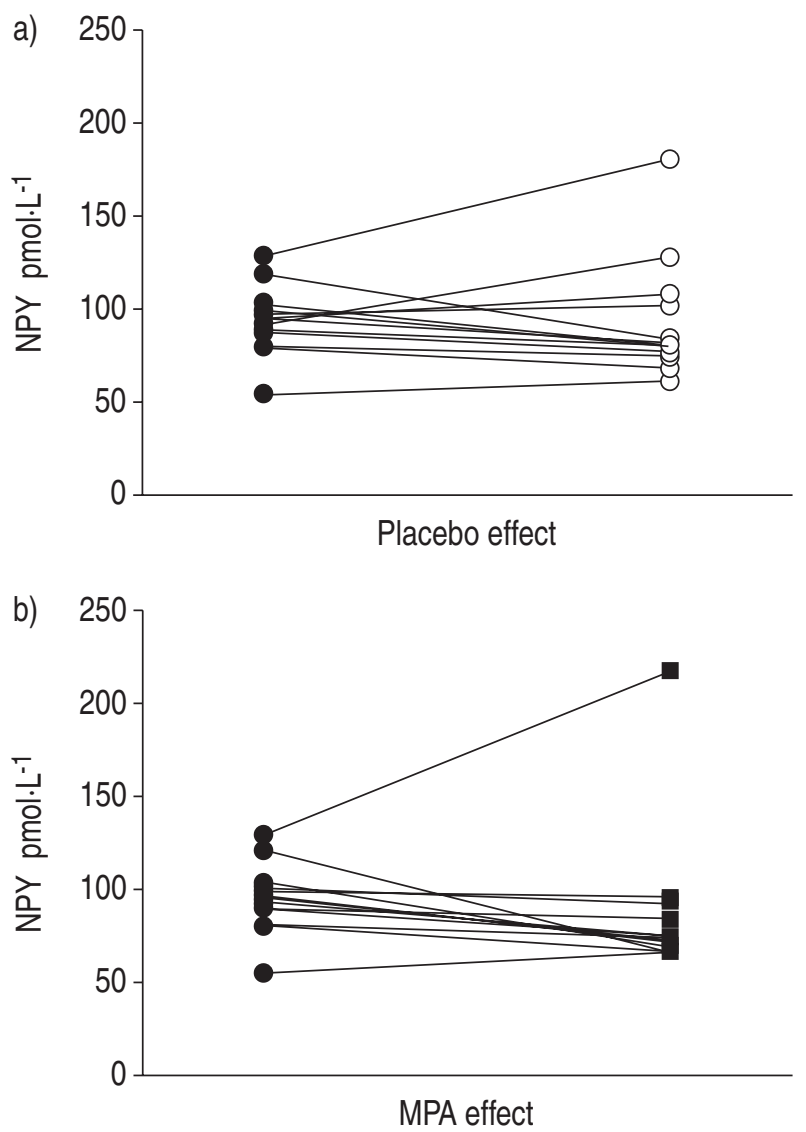

Fig. 3.-Serum concentrations of neuropeptide Y (NPY) at baseline with a) placebo and b) after 2 weeks of treatment with medroxyprogesterone acetate (MPA). baseline values; $\bigcirc$ values with placebo; values with MPA. 
remained nonsignificant $(\mathrm{p}=0.251)$. The $\mathrm{p}$-values for $\mathrm{HCO}_{3}{ }^{-}$concentration and $\mathrm{BE}$ changes remained at the same level of significance $(\mathrm{p}<0.0001)$. Changes for $\mathrm{pH}$, leptin and NPY did not reach significance. The correlation between changes in serum leptin levels and changes in $\mathrm{Pa}_{\mathrm{a}} \mathrm{CO}_{2}$ was significant $(\mathrm{r}=0.60, \mathrm{p}=0.031$, fig. 4). All other correlations between leptin or NPY and arterial blood gases or BMI were nonsignificant.

\section{Discussion}

In postmenopausal females with respiratory impairment, MPA effectively reduced $\mathrm{Pa}_{2} \mathrm{CO}_{2}$ levels. The average $\mathrm{Pa}, \mathrm{CO}_{2}$ decrease of $0.8 \mathrm{kPa}$ was comparable to that observed in a previous study by SAARESRANTA et al. [12]. Although the average levels of serum leptin did not change on MPA, there was a correlation between the decrease in $\mathrm{Pa}, \mathrm{CO}_{2}$ levels and decrease in serum leptin levels. The results could be explained by a dose-threshold effect, in which a decrease in $\mathrm{Pa}, \mathrm{CO}_{2}$ $\geqslant 0.9 \mathrm{kPa}$ is needed before serum leptin decreases (fig. 4). Serum NPY levels were not affected by MPA nor the $P \mathrm{a}, \mathrm{CO}_{2}$ response.

In obese mutant mice with leptin deficiency, leptin infusion increased ventilation [1]. The effect of leptin on ventilation was independent of weight, $\mathrm{CO}_{2}$ production and food intake, suggesting a direct effect of leptin on the central control of respiration. It was hypothesised that MPA, while improving ventilation, would increase serum leptin levels and decrease NPY, partly having its effect on breathing via altering the levels of these two hormones. However, the patients in this study showed that the serum leptin levels did not increase during MPA therapy although ventilation did. This is in contrast with the previous observations of increased leptin levels during states with simultaneously increased serum progesterone concentrations and increased ventilation, e.g. during the luteal phase of the menstrual cycle $[5,8,11,19,20]$ or during pregnancy [21]. Higher leptin levels have been

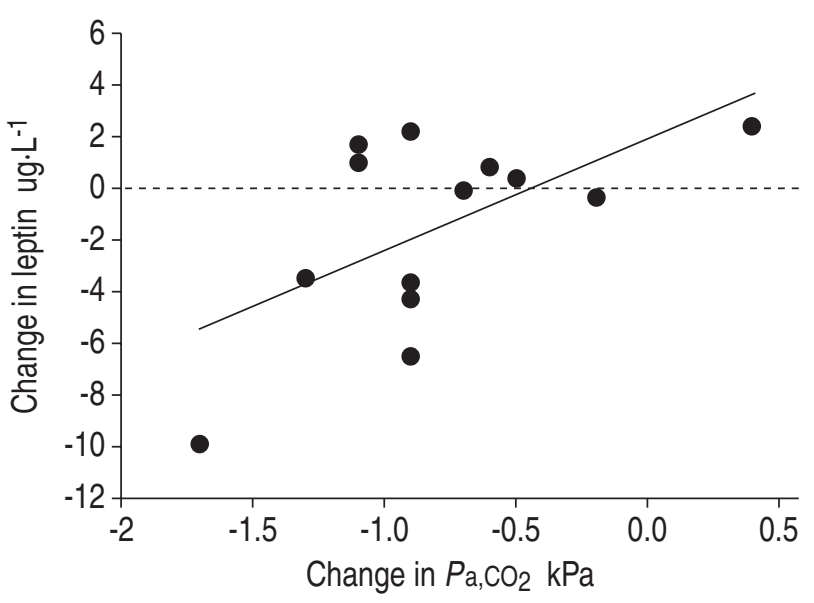

Fig. 4.-Changes in fasting serum leptin concentration versus changes in the carbon dioxide pressure in arterial blood $\left(P \mathrm{a}, \mathrm{CO}_{2}\right)$ in postmenopausal females with moderate-to-severe chronic respiratory impairment showing a positive correlation $(\mathrm{r}=0.60$, $\mathrm{p}=0.031)$. reported in premenopausal females compared with postmenopausal $[7,8]$ although this finding has not been confirmed by all studies in this field [22, 23]. Some authors have observed a positive correlation between leptin and progesterone levels [5, 11, 20], whereas others have not $[21,24]$.

Recent studies in obstructive sleep apnoea syndrome (OSAS) and obesity hypoventilation syndrome support the present study. Obese hypercapnic patients have higher fasting serum leptin levels than obese eucapnic patients, and serum leptin more reliably predicts the presence of hypercapnia than the percentage of body fat [25]. Serum leptin levels decrease with nasal continuous positive airway pressure (CPAP) treatment [26, 27] without changes in body weight [27]. Because nasal CPAP treatment improves ventilation and decreases $\mathrm{CO}_{2}$ levels [14], an association between decreased leptin levels and decreased $\mathrm{CO}_{2}$ levels in these studies may be assumed, although neither arterial, transcutaneous nor end-tidal $\mathrm{CO}_{2}$ levels were not measured.

The present study population was heterogeneous in terms of hypercapnia and BMI. Four of the patients had a $\mathrm{BMI}>30 \mathrm{~kg} \cdot \mathrm{m}^{-2}$ and four had a $P \mathrm{a}, \mathrm{CO}_{2} \geqslant 6.0 \mathrm{kPa}$, one patient had both. This heterogeneity may have influenced the results. Patients in previous studies of the association between serum leptin levels and breathing have been obese with OSAS or obesity hyperventilation syndrome, and hyperleptinaemia has been linked with possible obesity-related leptin resistance [25-27]. Most of the patients in this study were lean, and their weight remained stable during the study. Therefore, the positive correlation between changes in serum leptin levels and $\mathrm{Pa}, \mathrm{CO}_{2}$ levels was not related to obesity nor to weight changes. Leptin levels, in the patients in this study, were not high probably because they were neither obese nor hypercapnic [25]. Both leptin [1] and MPA are powerful respiratory stimulants. When the upper airway is unloaded and the $\mathrm{CO}_{2}$ levels are decreased, with the help of nasal CPAP or with a respiratory stimulant such as MPA (as in the present study), lower leptin levels are no longer needed to support ventilation.

The existence of states with increased serum leptin and progesterone supports the association between leptin and endogenously high progesterone concentrations. However, a synthetic progestin MPA was used in this study, the effect of which on leptin may differ from that of endogenous progesterone. In ovariectomised females on progesterone plus oestradiol replacement therapy, progesterone increased leptin secretion regardless of oestradiol concentration [6]. In postmenopausal females, combined hormone replacement therapy with continuous conjugated oestrogens $\left(0.625 \mathrm{mg} \cdot \mathrm{day}^{-1}\right)$ for $11 \mathrm{months}$ and MPA $\left(5 \mathrm{mg} \cdot\right.$ day $^{-1}$ for 13 days every third month) had no effect on serum leptin levels [28]. Addition of progesterone (100 $\mathrm{mg}$ per vagina $b . i . d$.) to transdermal oestrogen therapy had no effect on serum leptin concentrations [29]. To the best of the authors' knowledge there have been no previous reports on the effect of plain progestin therapy on leptin levels.

This study also found that serum NPY concentrations did not change during MPA therapy. NPY levels 
increase during pregnancy [30] and during the menopause [9]. These findings suggest that NPY is unrelated to serum progesterone concentrations, although correlations between progesterone and NPY levels were not evaluated. In animal studies, the respiratory rate decreased after central administration of NPY [2]. The role of NPY in human control of breathing is not established, but some data suggest that it might play a role. A post mortem study in 19 patients showed that those with very high NPY levels in the infundibular nucleus had suffered from respiratory failure for at least 10 days before death, whereas patients with low levels of NPY had died either within 2 days of the onset of cardiorespiratory disorders or of unrelated causes [31]. The effect of progestin therapy on NPY concentrations has not been elucidated previously. Although the results from this study showed no significant effect of MPA on serum NPY levels, there is a high risk of a type II error due to the small sample size and high variability in the levels of serum NPY. Therefore, the possibility that MPA would have an effect on serum NPY levels cannot be excluded.

Short-term progestin therapy effectively improved ventilation and decreased the carbon dioxide tension in arterial blood in postmenopausal females with chronic respiratory impairment. Although medroxyprogesterone acetate did not alter serum leptin or neuropeptide $\mathrm{Y}$ levels, the decrease in the carbon dioxide tension in arterial blood was associated with a decrease in serum leptin levels. Unfortunately, the present study was underpowered to observe changes in serum neuropeptide $\mathrm{Y}$. The present observations support an association of leptin with the control of breathing in human subjects. Whether the changes in leptin concentration observed in the present study, are secondary to the changes in the carbon dioxide tension in arterial blood or contribute actively to respiratory stimulation during hypercapnia remains to be elucidated.

\footnotetext{
Acknowledgements. The authors would like to thank E. Wallius, for statistical assistance and Orion Pharma, Espoo, Finland for the supply of medication.
}

\section{References}

1. O'Donnell CP, Schaub CD, Haines AS, et al. Leptin prevents respiratory depression in obesity. Am J Respir Crit Care Med 1999; 159: 1477-1484.

2. Härfstrand A. Brain neuropeptide Y mechanisms. Basic aspects and involvement in cardiovascular and neuroendocrine regulation. Acta Physiol Scand 1987; 131: Suppl. 565, 1-83.

3. Morton KD, McCloskey MJD, Potter EK. Cardiorespiratory responses to intracerebroventricular injection of neuropeptide $\mathrm{Y}$ in anaesthetized dogs. Regul Pept 1999; 81: 81-88.

4. Frühbeck G, Jebb SA, Prentice AM. Leptin: physiology and pathophysiology. Clin Physiol 1998; 18: $399-419$.
5. Hardie L, Trayhurn P, Abramovich D, Fowler P. Circulating leptin in women: a longitudinal study in the menstrual cycle and during pregnancy. Clin Endocrinol 1997; 47: 101-106.

6. Messinis IE, Kariotis I, Milingos S, Kollios G, Seferiadis K. Treatment of normal women with oestradiol plus progesterone prevents the decrease of leptin concentrations induced by ovariectomy. Hum Reprod 2000; 15: 2383-2387.

7. Rosenbaum M, Nicolson M, Hirsch J, et al. Effects of gender, body composition, and menopause on plasma concentrations of leptin. J Clin Endocrinol Metab 1996; 81: 3424-3427.

8. Shimizu H, Shimomura Y, Nakanishi $\mathrm{Y}$, et al. Estrogen increases in vivo leptin production in rats and human subjects. J Endocrinol 1997; 154: 285-292.

9. Baranowska B, Radzikowska M, WasilewskaDziubinska E, Roguski K, Polonowski A. Relationship among leptin, neuropeptide $\mathrm{Y}$, and galanin in young women and in postmenopausal women. Menopause 2000; 7: 149-155.

10. Bixler EO, Vgontzas AN, Lin H-M, et al. Prevalence of sleep-disordered breathing in women: effects of gender. Am J Respir Crit Care Med 2001; 163: 608-613.

11. Mannucci E, Ognibene A, Becorpi A, et al. Relationship between leptin and oestrogens in healthy women. Eur J Endocrinol 1998; 139: 198-201.

12. Saaresranta T, Polo-Kantola P, Irjala K, Helenius H, Polo O. Respiratory insufficiency in postmenopausal women: sustained improvement of gas exchange with short-term medroxyprogesterone acetate. Chest 1999; 115: $1581-1587$.

13. Block AJ, Wynne JW, Boysen PG, Lindsey S, Martin C, Cantor B. Menopause, medroxyprogesterone and breathing during sleep. Am J Med 1981; 70: 506-510.

14. Saaresranta T, Polo-Kantola P, Rauhala E, Polo O. Medroxyprogesterone in postmenopausal females with partial upper airway obstruction during sleep. Eur Respir J 2001; 18: 989-995.

15. Skatrud JB, Dempsey JA, Kaiser DG. Ventilatory response to medroxyprogesterone acetate in normal subjects: time course and mechanism. J Appl Physiol 1978; 44: 939-944.

16. Zwillich CW, Natalino MR, Sutton FD, Weil JV. Effects of progesterone on chemosensitivity in normal men. J Lab Clin Med 1978; 92: 262-269.

17. Saaresranta T, Irjala K, Polo-Kantola P, Helenius H, Polo O. Prolonged endocrine responses to medroxyprogesterone in postmenopausal women with respiratory insufficiency. Obstet Gynecol 2000; 96: 243-249.

18. Jones B, Kenward MG. Design and analysis of crossover trials. London, Chapman and Hall, 1989.

19. Quinton ND, Laird SM, Okon MA, et al. Serum leptin levels during the menstrual cycle of healthy fertile women. Br J Biomed Sci 1999; 56: 16-19.

20. Cella F, Giordano G, Cordera R. Serum leptin concentrations during the menstrual cycle in normalweight women: effects of an oral triphasic estrogenprogestin medication. Eur J Endocrinol 2000; 142: 174-178.

21. Stock SM, Sande EM, Bremme KA. Leptin levels vary significantly during the menstrual cycle, pregnancy, and in vitro fertilization treatment: possible relation to estradiol. Fertil Steril 1999; 72: 657-662.

22. Di-Carlo C, Tommaselli GA, Pisano G, et al. Serum 
leptin levels in postmenopausal women: effects of transdermal hormone replacement therapy. Menopause 2000; 7: 36-41.

23. Saad MF, Damani S, Gingerich RL, et al. Sexual dimorfism in plasma leptin concentration. $J$ Clin Endocrinol Metab 1997; 82: 579-584.

24. Teirmaa T, Luukkaa V, Rouru J, Koulu M, Huupponen R. Correlation between circulating leptin and luteinizing hormone during the menstrual cycle in normal-weight women. Eur J Endocrinol 1998; 139: 190-194.

25. Phipps PR, Starritt E, Caterson I, Grunstein RR. Association of serum leptin with hypoventilation in human obesity. Thorax 2002; 57: 75-76.

26. Saarelainen S, Lahtela J, Kallonen E. Effect of nasal CPAP treatment on insulin sensitivity and plasma leptin. J Sleep Res 1997; 6: 146-147.

27. Chin K, Shimizu K, Nakamura T, et al. Changes in intra-abdominal visceral fat and serum leptin levels in patients with obstructive sleep apnea syndrome following nasal continuous positive airway pressure therapy. Circulation 1999; 100: 706-712.

28. Kohrt WM, Landt M, Birge SJJ. Serum leptin levels are reduced in response to exercise training, but not hormone replacement therapy, in older women. $J$ Clin Endocrinol Metab 1996; 81: 3980-3985.

29. Lavoie HB, Taylor AE, Sharpless JL, Anderson EJ, Strauss CC, Hall JE. Effects of short-term hormone replacement on serum leptin levels in postmenopausal women. Clin Endocrinol 1999; 51: 415-422.

30. Khatun S, Kanayama N, Md Belayet $\mathrm{H}$, et al. Increased concentrations of plasma neuropeptide $\mathrm{Y}$ in patients with eclampsia and preeclampsia. Am J Obstet Gynecol 2000; 182: 896-900.

31. Corder R, Pralong FP, Muller AF, Gaillard RC. Regional distribution of neuropeptide Y-like immunoreactivity in human hypothalamus measured by immunoradiometric assay: possible influence of chronic respiratory failure on tissue levels. Neuroendocrinology 1990; 51: 23-30. 